\title{
Relationship of Clinical Nursing Competence to Nursing Occupational Experience in Hospice/Palliative Care Nurses in Japan
}

\author{
Kaori Tsutsumi, Keiko Sekido \\ Department of Nursing, Kobe University Graduate School of Health Sciences, Kobe, Japan \\ Email: kaottmi@iris.eonet.ne.jp
}

Received 2 January 2015; accepted 15 February 2015; published 16 February 2015

Copyright (C) 2015 by authors and Scientific Research Publishing Inc.

This work is licensed under the Creative Commons Attribution International License (CC BY). http://creativecommons.org/licenses/by/4.0/

(c) (i) Open Access

\section{Abstract}

Aim: The purpose of this research is to examine the relationship between the clinical nursing competence and nursing occupational experience in hospice/palliative care nurses (HPN) in Japan. Methods: A mail survey using an anonymous self-administered questionnaire was conducted on clinical nursing competence regarding communication, care and prediction of worsening of symptoms with the authors' previous research as a framework. The subjects were nurses working in hospice/palliative care units in Japan, and the period of survey was January to February, 2014. Results: In this study, the relationship between the clinical nursing competence and nursing occupational experience of HPNs in hospice/palliative care which was clarified in the authors' previous research was examined. The results showed that the amount of clinical nursing experience as a nurse was related to clinical nursing competence in the care of end-of-life patients and worsening of symptoms. The abundance of specialized nursing experience was also related to clinical nursing competence in communication in addition to care and prediction of worsening of symptoms. Training experience was also shown to be effective for hospice/palliative care. Conclusion: From these results, clinical nursing competence of HPNs in care of end-of-life patients and prediction of worsening of symptoms are possibly learned through the accumulation of clinical nursing experience as a nurse. However, HPN's clinical nursing competence in communication was suggested to be developed through nursing practice in hospice/palliative care.

\section{Keywords}

Hospice and Palliative Care Nursing, Clinical Nursing Competence, Nursing Occupational Experience 


\section{Introduction}

There are many patients who require hospice/palliative care in Japan, including those with cancer. High quality nursing skills is especially needed in hospice/palliative care facilities, as places where end-of-life patients receive care. Therefore, the authors conduct qualitative research on the characteristics of nursing for end-of-life patients, using nurses other than specialized and certified nurses working in hospice/palliative care units as subjects. The results show that hospice/palliative care requires outstanding clinical nursing competence while supporting patients who are approaching a natural death [1]. Specialized nurses and certified nurses for end-of-life care are gradually increasing in Japan [2], but general nurses are also numerous. General nurses need to enhance their skills while learning a variety of knowledge and technology from nursing practice. There have been many reports on clinical nursing competence [3]-[6]. Clinical nursing competence has been reported to increase with years of experience [7]-[9]. This is the result from examining the years of service as general nurses, but we have not found any reports examining nursing occupational experience in hospice/palliative care units.

The purpose of this research is to examine the relationship between clinical nursing competence and nursing occupational experience in hospice/palliative care nurses. We believe that such an investigation can be useful in career support for hospice/palliative care nurses.

\section{Methods}

\subsection{Study Design}

This study used a quantitative research design.

The conceptual framework of this study was derived from the authors' qualitative research as shown in the figure (see Figure 1). A common characteristic of nursing by hospice/palliative care nurses (HPN) is "support for patients approaching a natural death", which is the foundation of nursing practice by an HPN: communication, care and prediction of worsening of symptoms. Therefore, the questionnaire for this study was structured to ask about the practice of communication (10 questions), care (8 questions) and prediction of worsening of symptoms (5 questions) as items of clinical nursing competence. The questionnaires were answered on a five point scale from "Very true" (5 points) to "Not at all true" (1 point).

\subsection{Definitions of Terms}

-End-of-life: the status of a person who cannot be cured, even with the application of multidisciplinary treatment, and aggressive treatment is rather considered to be inappropriate for the patient. Life prognosis is usually considered to be 6 months or less [10].

-Nursing occupational experience: nursing occupational experience includes clinical nursing experience, specialized nursing experience and training experience. Clinical nursing experience is experience working in a hospital, including experience in a hospice/palliative care unit. Specialized nursing experience is experience working in a hospice/palliative care unit. Training experience is training to care for end-of-life patients.

- Clinical nursing competence: Implementation of communication with end-of-life patients, care for end-oflife patients, and prediction of worsening of symptoms, which the authors clarified in previous research, are defined as clinical nursing competence.

\subsection{Data Collection}

This study was conducted as a mail survey using an anonymous self-administered questionnaire with HPNs as subjects. In November 2013, we made requests to 263 facilities registered with Hospice Palliative Care Japan and obtained consent from 70 facilities (26.6\%). The questionnaires were mailed to the 70 facilities/1429 HPNs and responses were received from 1003HPNs (response rate: 70.1\%). The subjects were the 958 respondents who answered to all questions (valid response rate: 96.1\%). The target number of valid respondents was 1000 . Therefore, we achieved the intended quality. Data collection was from January to February 2014.

\subsection{Data Analysis}

Nursing occupational experience as an HPN was classified into 5 groups of clinical nursing experience (less 


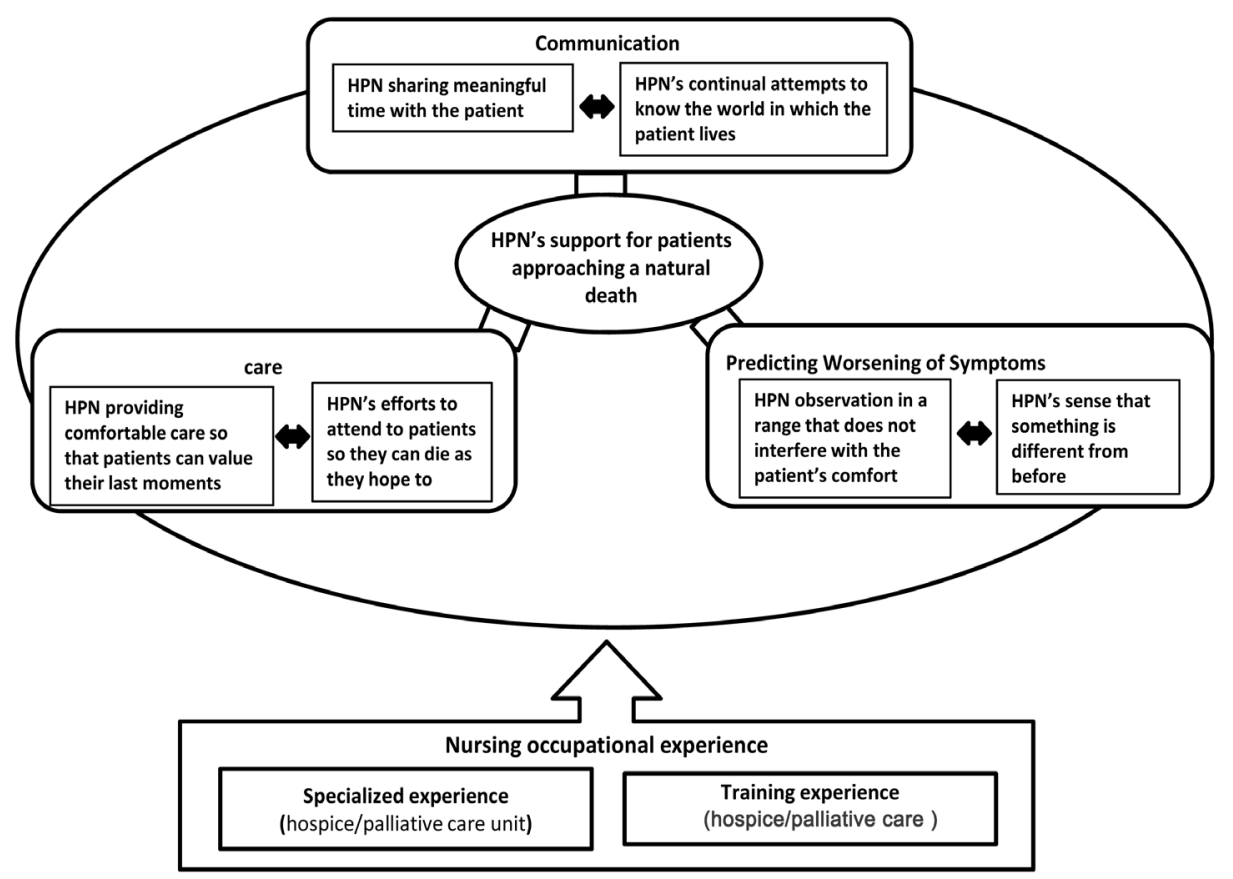

Figure 1. The conceptual framework of this study.

than 5 years, 5 to less than 10 years, 10 to less than 15 years, 15 to less than 20 years, and 20 years or more), 3groups of specialized nursing experience (less than 2 years, 2 to less than 5 years, and 5 years or more) and 2 groups of training experience (yes/no). In order to verify the relationship between the clinical nursing competence of an HPN and Nursing occupational experience as an HPN, unpaired analysis of variance for 1 factor was performed (in the case of equal variance), with clinical nursing experience and specialized nursing experience as independent variables and 25 clinical nursing competencies as dependent variables. Multiple comparison (Scheffe test) was performed on clinical nursing competencies in which significant difference was observed. If equal variance was not observed, the Kruskal-Wallis test was performed, and multiple comparisons (Scheffe test) were performed on clinical nursing competencies with significant difference. The Mann-Whitney U test was used to compare the 2 groups of training experience. A significance level of less than $5 \%$ was adopted.

\subsection{Ethical Considerations}

In requesting the survey, letters of request explaining the gist of the research were first sent to the representative of the facility and the nursing management representative. Upon obtaining consent we requested distribution of the questionnaires to subjects. A document on the voluntary nature of participation in the survey and freedom to withdraw, the advantages and disadvantages of participation in the survey, protection of personal information, publication of research results and handling before and after the study was provided to the subjects, and its return with the questionnaire was taken as consent.

This study was conducted with approval (No. 222) of the Kobe University Graduate School of Health Sciences Ethics Committee.

\section{Results}

\subsection{Characteristics of the Participants}

The subjects were 30 men (3.1\%) and 928 women (96.9\%). In age, 164 (17.1\%) were under 30 years, 367 (38.3\%) were 30 to less than 40 years, 284 (29.6\%) were 40 to less than 50 years, and 143 (14.9\%) were 50 years or over. Average clinical nursing experience as a nurse was $15.92 \pm 8.69$ years, and average specialized nursing experience $3.59 \pm 2.90$ years. There were 726 (75.8\%) who had training experience. 
Cronbach’s $\alpha$ for questionnaire (23 items) was 0.94 .

\subsection{Relationship of Clinical Nursing Competence and Nursing Occupational Experience}

1) Relationship with Clinical nursing Experience (Tables 1(a)-(c))

In the results of analysis, the clinical nursing competencies of HPNs that showed significant difference among the 5 groups of clinical nursing experience were: in care [HPN matches care to the patient's condition and needs that differ by the day, $(\mathrm{F}(4,953)=2.88, \mathrm{p}<0.05)$ ], [HPN judges the need for medical treatment from the suffering of the patient, $(\mathrm{F}(4,953)=3.63, \mathrm{p}<0.05)]$ and [HPN accepts the patients dying as they hope to, $(\mathrm{F}$ $(4,953)=3.75, \mathrm{p}<0.01)$ ]; and in prediction of worsening of symptoms [HPN checks the patient's temperature, pulse, respiration and reflexes by directly touching the patient's body, $(\mathrm{F}(4,953)=5.30, \mathrm{p}<0.01)]$, $[\mathrm{HPN}$ chooses measuring methods with the least burden according to the patient's condition, $(\mathrm{F}(4,953)=4.19, \mathrm{p}<$ $0.01)]$, [HPN is sensitive to day-to-day changes, $(\mathrm{F}(4,953)=7.48, \mathrm{p}<0.01)]$ and $[\mathrm{HPN}$ senses that the time of death is near, $(\mathrm{F}(4,953)=5.96, \mathrm{p}<0.01)]$.

In the results of multiple comparisons by the Scheffe test, each clinical nursing competency was significantly higher in HPNs with longer clinical nursing experience than in the group with less than 5 years' experience.

There were no significant differences concerning communication in HPN clinical nursing competency or clinical Nursing experience.

2) Relationship with Specialized Nursing Experience (Tables 2(a)-(c))

In the results of analysis, significant differences among the 3 groups of specialized nursing experience were: in communication [HPN has a sense of proper distance from the patient, not too close or far $(\mathrm{F}(2,955)=5.04$, $\mathrm{p}$ $<0.05)$ ], [HPN listens to patients with an open mind, without being skeptical $(\mathrm{F}=(2,955) 3.60, \mathrm{p}<0.05)$ ], [HPN shares time with patients in silence $(\mathrm{F}(2,955)=4.90, \mathrm{p}<0.05)]$ and [HPN builds up relationships with patients $(\mathrm{F}(2,955)=3.61, \mathrm{p}<0.05)]$; in care [HPN matches care to the patient's condition and needs that differ by the day $\left(\chi^{2}\right.$ value $\left.=14.19, \mathrm{p}<0.01\right)$ ], [HPN judges the need for medical treatment from the suffering of the patient $(\mathrm{F}(2,955)=5.63, \mathrm{p}<0.01)]$, [HPN tries to have the patient spend quality time with the family $(\mathrm{F}(2,955)$ $=8.20, \mathrm{p}<0.01)]$, [HPN cooperates with staff to provide better care $\left(\chi^{2}\right.$ value $\left.\left.=8.74, \mathrm{df} 2, \mathrm{p}<0.05\right)\right]$ and [HPN accepts the patients dying as they hope to $\left(\chi^{2}\right.$ value $=17.94$, $\left.\left.\mathrm{df} 2, \mathrm{p}<0.01\right)\right]$; and in prediction of worsening of symptoms [HPN checks the patient's temperature, pulse, respiration and reflexes by directly touching the patient's body $(\mathrm{F}(2,955)=7.06, \mathrm{p}<0.01)$ ], [HPN chooses measuring methods with the least burden according to the patient's condition $(\mathrm{F}(2,955)=10.80, \mathrm{p}<0.01)$ ], [HPN is sensitive to day-to-day changes $\left(\chi^{2}\right.$ value $=28.80$, df 2, $\mathrm{p}<0.01)$ ], [HPN senses something is different overall from the patient than before $(\mathrm{F}(2,955)=6.68, \mathrm{p}<$ $0.01)]$ and [HPN senses that the time of death is near, $\left(\chi^{2}\right.$ value $\left.\left.=27.56, \mathrm{df} 2, \mathrm{p}<0.01\right)\right]$.

In the results of multiple comparisons, each clinical nursing competency was significantly higher in HPNs with longer clinical nursing experience than in the group with less than 2 years' experience.

3) Relationship to Training Experience (Table 3)

In the results of the Mann-Whitney U test, significant differences between the 2 groups of training experience were: in communication [HPN creates a place where patients can talk about what they want to $(\mathrm{p}<0.05)$ ], [HPN intentionally makes time to be together with patients $(\mathrm{p}<0.01)$ ], [HPN gauges the pace and timing at which apatient wants to talk $(\mathrm{p}<0.05)$ ], [HPN sits and listens to patients carefully with eye contact $(\mathrm{p}<0.05)$ ], [HPN listens to patients with an open mind, without being skeptical $(\mathrm{p}<0.05)$ ], [HPN shares time with patients in silence ( $\mathrm{p}<0.01)$ ], [HPN faces the patient's hardships ( $<<0.05)$ ] and [HPN builds up relationships with patients, $\mathrm{p}<0.01$ ]; in care [HPN matches care to the patient's condition and needs that differ by the day $(\mathrm{p}<0.05)$ ], [HPN tries to fulfill a patient's modest hopes $(\mathrm{p}<0.01)$ ] [HPN judges the need for medical treatment from the suffering of the patient $(\mathrm{p}<0.05)$ ], [HPN cooperates with staff to provide better care $(\mathrm{p}<0.05)$ ], [HPN tries to have the patient spend quality time with the family $(\mathrm{p}<0.01)$ ], [HPN accepts the patients dying as they hope to $(p<0.01)]$ and [HPN wants to give care that enables the patient to meet the end they hope for $(p<0.01)]$; and in prediction of worsening of symptoms [HPN checks the patient's temperature, pulse, respiration and reflexes by directly touching the patient's body $(\mathrm{p}<0.01)$ ], [HPN chooses measuring methods with the least burden according to the patient's condition ( $\mathrm{p}<0.01$ )], [HPN is sensitive to day-to-day changes ( $<<0.01$ )], [HPN senses something is different overall from the patient than before $(\mathrm{p}<0.01)]$ and [HPN senses that the time of death is near $(\mathrm{p}<0.01)]$.

Each clinical nursing competency was higher in the group with HPN training experience than in the group without. 
Table 1. (a)-(c) Comparison of the clinical nursing competence of HPNs: nursing occupational experience $\mathrm{n}=958$.

(a)

\begin{tabular}{|c|c|c|c|c|c|c|c|}
\hline \multirow[b]{2}{*}{ framework } & \multirow[b]{2}{*}{ questions* } & \multicolumn{5}{|c|}{ Mean(SD) } & \multirow[b]{2}{*}{$\mathrm{F}$} \\
\hline & & $\begin{array}{l}\text { less than } \\
5 \text { years }\end{array}$ & $\begin{array}{c}5 \text { to less than } \\
10 \text { years }\end{array}$ & $\begin{array}{c}10 \text { to less than } \\
15 \text { years }\end{array}$ & & $\begin{array}{c}20 \text { years or } \\
\text { more }\end{array}$ & \\
\hline \multirow[t]{10}{*}{ Communication } & - creates a place where patients can talk about what they want to & $3.23(0.91)$ & $3.27(0.79)$ & $3.29(0.77)$ & $3.46(0.77)$ & $3.42(0.78)$ & 2.78 \\
\hline & - intentionally makes time to be toget her with patients & $3.29(0.91)$ & $3.34(0.83)$ & $3.43(0.83)$ & $3.42(0.75)$ & $3.39(0.78)$ & 0.67 \\
\hline & -gauges the pace and timing at which a patient wants to talk & $3.66(0.75)$ & $3.62(0.74)$ & $3.74(0.76)$ & $3.77(0.76)$ & $3.76(0.80)$ & 1.32 \\
\hline & - haves a sense of proper distance from the patient, not too close or far & $3.26(0.79)$ & $3.46(0.70)$ & $3.56(0.78)$ & $3.55(0.76)$ & $3.46(0.80)$ & 2.35 \\
\hline & - sits and listens to patients carefully with eye contact & $3.92(0.82)$ & $3.91(0.82)$ & $3.92(0.89)$ & $4.01(0.77)$ & $4.00(0.81)$ & 0.75 \\
\hline & - listens to patients patiently without interrupting, even if it takes time & $3.44(0.74)$ & $3.49(0.77)$ & $3.54(0.76)$ & $3.61(0.78)$ & $3.63(0.76)$ & 1.68 \\
\hline & - listens to patients with an open mind, without being skeptical & $3.53(0.86)$ & $3.42(0.77)$ & $3.52(0.77)$ & $3.61(0.77)$ & $3.63(0.74)$ & 2.58 \\
\hline & -shares time with patients in silence & $3.34(0.87)$ & $3.37(0.80)$ & $3.43(0.82)$ & $3.56(0.80)$ & $3.50(0.81)$ & 0.11 \\
\hline & - tries to know the patient's suffering and pain & $3.76(0.76)$ & $3.69(0.68)$ & $3.74(0.79)$ & $3.81(0.76)$ & $3.80(0.79)$ & 0.80 \\
\hline & - builds up relationships with patients & $3.69(0.74)$ & $3.72(0.69)$ & $3.81(0.78)$ & $3.83(0.78)$ & $3.81(0.79)$ & 0.89 \\
\hline
\end{tabular}

(b)

\begin{tabular}{|c|c|c|c|c|c|c|c|}
\hline \multirow[b]{2}{*}{ framework } & \multirow[b]{2}{*}{ questions* } & \multicolumn{5}{|c|}{ Mean(SD) } & \multirow[b]{2}{*}{$\mathrm{F}$} \\
\hline & & $\begin{array}{l}\text { less than } \\
5 \text { years }\end{array}$ & $\begin{array}{c}5 \text { to less than } \\
10 \text { years }\end{array}$ & $\begin{array}{c}10 \text { to less than } \\
15 \text { years }\end{array}$ & $\begin{array}{c}15 \text { to less than } \\
20 \text { years }\end{array}$ & $\begin{array}{c}20 \text { years or } \\
\text { more }\end{array}$ & \\
\hline & & \multicolumn{5}{|c|}{$*$} & \\
\hline \multirow[t]{12}{*}{ Care } & - matches care to the condition and wishes of the patient & $3.56(0.80)$ & $3.79(0.75)$ & $3.86(0.77)$ & $3.94(0.75)$ & $3.82(0.80)$ & 2.88 \\
\hline & - tries to fulfill a patient's modest wishes & $3.82(0.74)$ & $3.95(0.77)$ & $3.94(0.76)$ & $4.03(0.75)$ & $3.98(0.79)$ & 0.95 \\
\hline & - provides the best possible care & $3.76(0.78)$ & $3.81(0.85)$ & $3.80(0.82)$ & $3.76(0.84)$ & $3.73(0.82)$ & 0.34 \\
\hline & & \multirow{2}{*}{\multicolumn{6}{|c|}{$*$}} \\
\hline & & & & & & & \\
\hline & -judges the need for medical treatment from the suffering of the patient & $3.55(0.86)$ & $3.77(0.78)$ & $3.84(0.76)$ & $3.92(0.77)$ & $3.91(0.80)$ & 3.63 \\
\hline & - tries to have the patient spend quality time with the family & $4.06(0.77)$ & $4.13(0.74)$ & $4.16(0.71)$ & $4.26(0.75)$ & $4.15(0.74)$ & 1.20 \\
\hline & $\cdot$ cooperates with staff to provide better care & $3.89(0.77)$ & $4.02(0.81)$ & $3.93(0.83)$ & $4.07(0.80)$ & $4.07(0.80)$ & 1.59 \\
\hline & & \multirow{2}{*}{\multicolumn{5}{|c|}{$*$}} & \\
\hline & & * & & & & & \\
\hline & -accepts the patients dying as they hope to & $3.68(0.84)$ & $3.98(0.77)$ & $3.88(0.79)$ & $4.05(0.84)$ & $4.03(0.78)$ & 3.75 \\
\hline & - wants to give care that enables the patient to meet the end they hope for & $4.13(0.91)$ & $4.29(0.75)$ & $4.26(0.77)$ & $4.39(0.73)$ & $4.28(0.78)$ & 1.49 \\
\hline
\end{tabular}

(c)

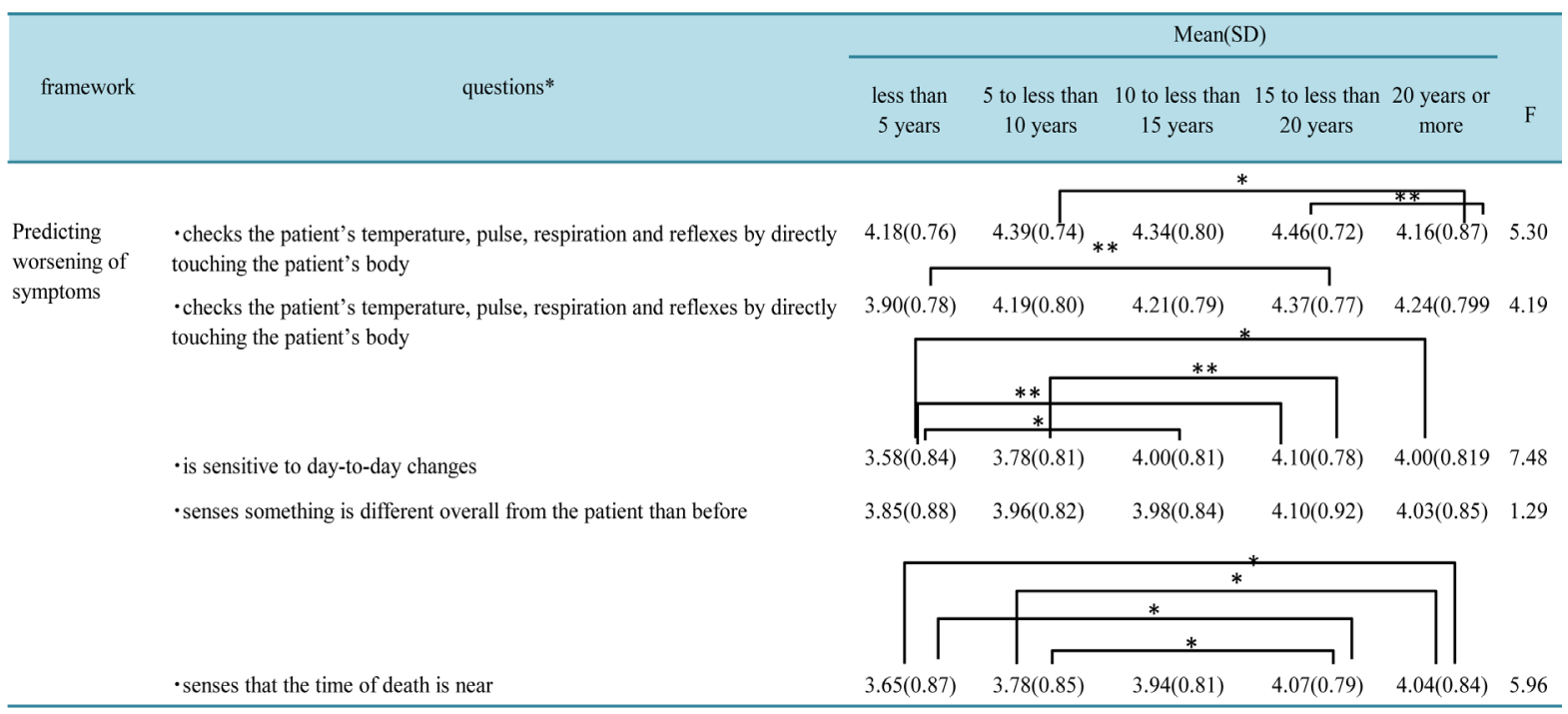

Notes: "The subject of text without the subject in questions is hospice/palliative care nurses (HPN). One-way analysis of variance, Scheffe's multiple comparison. Kruskal-Wallis test if equal variance was not observed. ${ }^{*} \mathrm{p}<0.05,{ }^{* *} \mathrm{p}<0.01$. 
Table 2. Comparison of the clinical nursing competence of HPNs: specialized nursing experience $(\mathrm{n}=958)$.

(a)

\begin{tabular}{|c|c|c|c|c|c|}
\hline \multirow[b]{2}{*}{ framework } & \multirow[b]{2}{*}{ questions } & \multicolumn{3}{|c|}{ Mean(SD) } & \multirow[b]{2}{*}{$F /(a): \chi^{2}$} \\
\hline & & $\begin{array}{c}\text { less than } 2 \\
\text { years }\end{array}$ & $\begin{array}{c}2 \text { to less than } \\
5 \text { years }\end{array}$ & 5 years or more & \\
\hline \multirow[t]{10}{*}{ Communication } & -creates a place where patients can talk about what they want to & $3.32(0.79)$ & $3.38(0.80)$ & $3.37(0.78)$ & 0.44 \\
\hline & - intentionally makes time to be toget her with patients & $3.35(0.84)$ & $3.38(0.77)$ & $3.44(0.81)$ & 1.09 \\
\hline & -gauges the pace and timing at which a patient wants to talk & $3.63(0.79)$ & $\begin{array}{c}3.75(0.76) \\
*\end{array}$ & $3.78(0.76)$ & 3.41 \\
\hline & - haves a sense of proper distance from the patient, not too close or far & $3.40(0.76)$ & $3.47(0.78)$ & $3.60(0.74)$ & 5.04 \\
\hline & -sits and listens to patients carefully with eye contact & $3.85(0.88)$ & $3.99(0.80)$ & $4.02(0.79)$ & $5.65^{(\mathrm{a})}$ \\
\hline & - listens to patients patiently without interrupting, even if it takes time & $3.52(0.78)$ & $\begin{array}{c}3.58(0.77) \\
* \\
\end{array}$ & $3.60(0.74)$ & 0.86 \\
\hline & - listens to patients with an open mind, without being skeptical & $3.46(0.77)$ & $\begin{array}{c}3.58(0.78) \\
*\end{array}$ & $3.62(0.75)$ & 3.63 \\
\hline & -shares time with patients in silence & $3.35(0.85)$ & $3.46(0.79)$ & $3.56(0.80)$ & 4.90 \\
\hline & -tries to know the patient's suffering and pain & $3.71(0.73)$ & $3.79(0.74)$ & $3.79(0.81)$ & 1.27 \\
\hline & - builds up relationships with patients & $3.69(0.75)$ & $3.81(0.77)$ & $3.85(0.77)$ & 3.61 \\
\hline
\end{tabular}

(b)

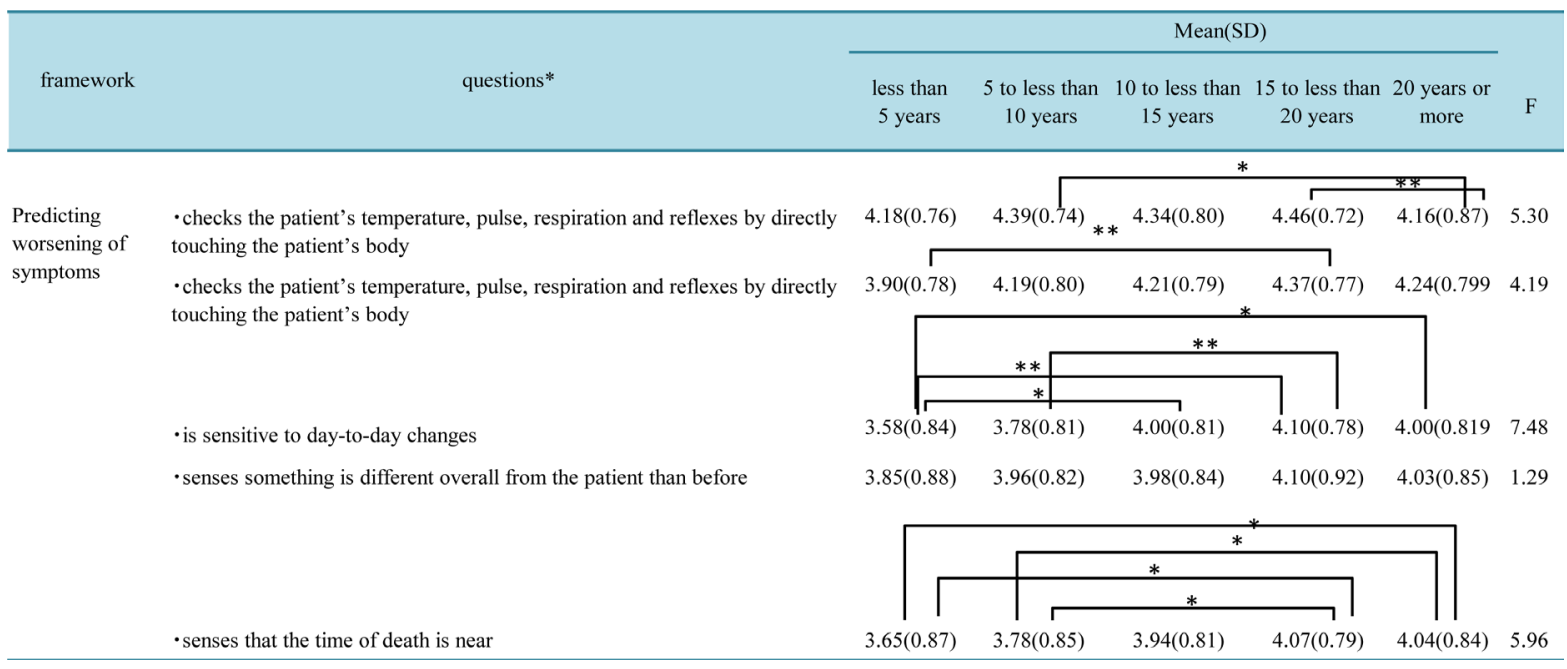

(c)

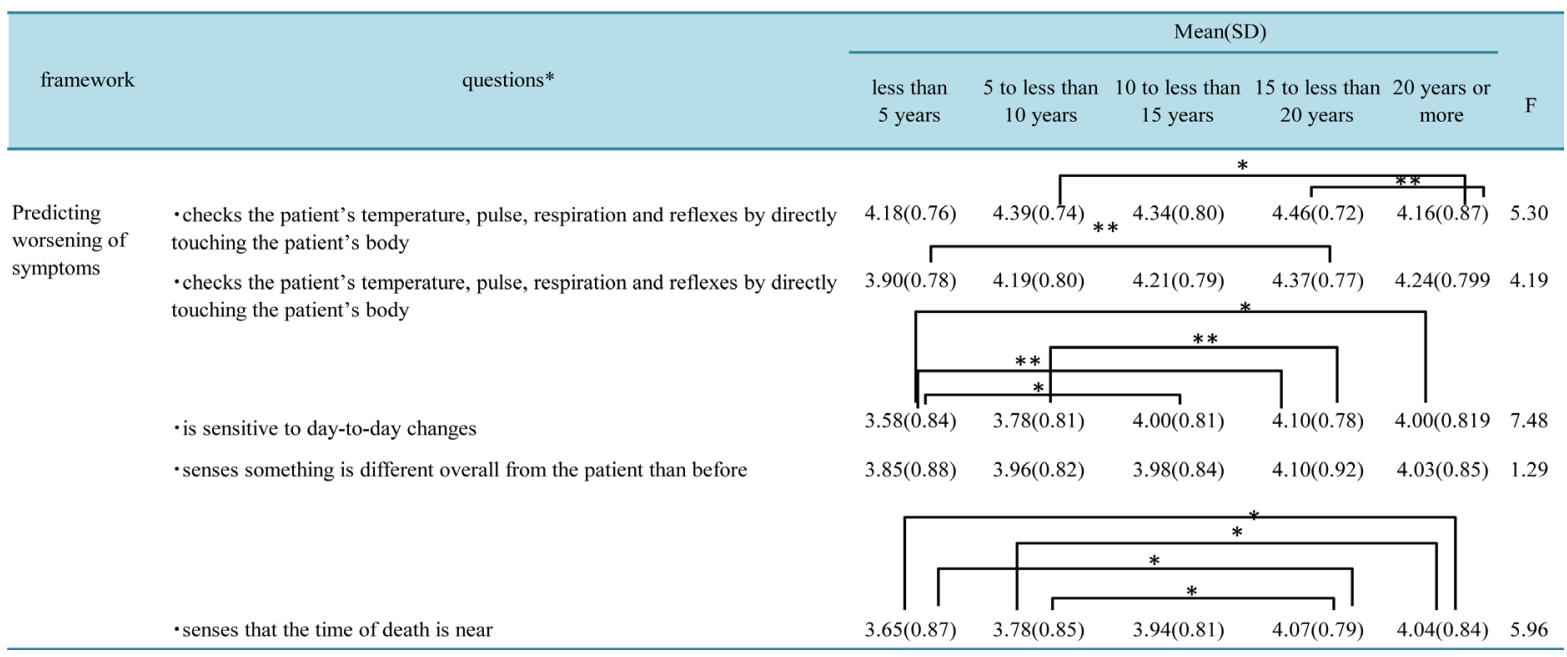

Notes: one-way analysis of variance, Scheffe's multiple comparison. Kruskal-Wallis test if equal variance was not observed. ${ }^{*} \mathrm{p}<0.05$, $* * \mathrm{p}<0.01$. 
Table 3. Comparison of the clinical nursing competence of HPNs: training experience (yes/no) $n=958$.

\begin{tabular}{|c|c|c|c|}
\hline framework & questions & Mean(SD) & $\mathrm{p}$ \\
\hline \multirow[t]{10}{*}{ Communication } & - creates a place where patients can talk about what they want to & $3.36(0.79)$ & * \\
\hline & - intentionally makes time to be toget her with patients & $3.39(0.80)$ & $* *$ \\
\hline & - gauges the pace and timing at which a patient wants to talk & $3.72(0.77)$ & * \\
\hline & - haves a sense of proper distance from the patient, not too close or far & $3.49(0.77)$ & n.s. \\
\hline & - sits and listens to patients carefully with eye contact & $3.96(0.82)$ & * \\
\hline & - listens to patients patiently without interrupting, even if it takes time & $3.57(0.76)$ & n.s. \\
\hline & - listens to patients with an open mind, without being skeptical & $3.56(0.77)$ & $*$ \\
\hline & - shares time with patients in silence & $3.46(0.81)$ & * \\
\hline & - tries to know the patient's suffering and pain & $3.77(0.76)$ & * \\
\hline & - builds up relationships with patients & $3.79(0.77)$ & ** \\
\hline \multirow[t]{8}{*}{ Care } & - matches care to the condition and wishes of the patient & $3.83(0.78)$ & $*$ \\
\hline & - tries to fulfill a patient's modest wishes & $3.97(0.76)$ & ** \\
\hline & - provides the best possible care & $3.77(0.83)$ & n.s. \\
\hline & - judges the need for medical treatment from the suffering of the patient & $3.83(0.79)$ & * \\
\hline & - tries to have the patient spend quality time with the family & $4.16(0.74)$ & ** \\
\hline & - cooperates with staff to provide better care & $4.02(0.81)$ & $*$ \\
\hline & - accepts the patients dying as they hope to & $3.97(0.80)$ & $* *$ \\
\hline & - wants to give care that enables the patient to meet the end they hope for & $4.29(0.77)$ & ** \\
\hline \multirow{5}{*}{$\begin{array}{l}\text { Predicting } \\
\text { worsening of } \\
\text { symptoms }\end{array}$} & - checks the patient's temperature, pulse, respiration and reflexes by directly touching the patient's body & $4.31(0.80)$ & ** \\
\hline & - checks the patient's temperature, pulse, respiration and reflexes by directly touching the patient's body & $4.23(0.79)$ & ** \\
\hline & - is sensitive to day-to-day changes & $3.95(0.82)$ & $* *$ \\
\hline & - senses something is different overall from the patient than before & $4.01(0.86)$ & $* *$ \\
\hline & - senses that the time of death is near & $3.95(0.84)$ & $* *$ \\
\hline
\end{tabular}

Notes: Mann-Whitney U test, Scheffe's multiple comparison. ${ }^{*} \mathrm{p}<0.05,{ }^{* *} \mathrm{p}<0.01$.

\section{Discussion}

HPNs with long clinical nursing experience had greater clinical nursing competence in matching care to the patient, accepting the patient's death and predicting the worsening of symptoms than HPNs with less than 5 years of clinical nursing experience. This tendency was particularly seen in HPNs with 15 to less than 20 years of experience. HPNs with more than 20 years of clinical nursing experience could predict the time of death. This shows that it is highly likely that abundant clinical nursing experience of an HPN influences clinical nursing competence in caring for end-of-life patients and predicting worsening of symptoms, and we infer that these competencies are learned through accumulated clinical nursing experience. Clinical nursing experience is an important process for the realization and growth of nursing expertise [11]. Nurses continue to actively acquire specialized knowledge and skills after employment [12] [13]. It is also said that clinical nursing competence shows stability after 5 years [14]. However, there are large individual differences, and it has also been reported that after a certain period of time, nurses experience slow progress in their improvement [7]. Therefore, clinical nursing experience is not simply a matter of passing years; continued support for HPNs is necessary so that they also gain qualitatively rich experience.

In hospice/palliative care, communication through a good patient-nurse relationship is the foundation of efective care [15] [16]. In this survey, no difference in the abundance of clinical nursing experience and clinical nursing competence in communication is seen. This result supports the report that communication skills cannot necessarily be developed even with clinical nursing experience as a nurse [17]. However, compared to HPNs 
with less than 2 years of specialized nursing experience, HPNs with longer specialized nursing experience have deepened relationships with patients while maintaining a sense of proper distance, an open mind and shared silences. It is known that HPNs with abundant experience have a positive attitude toward death [18] [19]. Being an excellent HPN is also said to involve personal characteristics such as kindness and warmth [16]. In our previous research, we reported that HPNs made efforts to not feel regrets at the death of a patient by giving the best care to the patient and engaging deeply with the patient [1]. All of this suggests that having general clinical nursing experience as a nurse is not enough to be skilled in the clinical nursing competence of communication, but is developed through accumulated nursing practice in the specialized field of a hospice/palliative care unit. It is also possible that the process of accumulating specialized nursing experience leads to having the patient spend quality time with the family and cooperating with staff to provide better care. In addition, HPNs with abundant specialized nursing experience were able to sense that "something is different in the patient" in the prediction of worsening of symptoms. This sense may also be developed through specialized nursing experience, showing observational skills.

Specialized nursing experience is accumulated with general clinical nursing experience as a nurse as the foundation. In contrast, a nurse with little clinical nursing experience can be expected to have various difficulties in the practice of hospice/palliative care nursing. Therefore, if aiming for hospice/palliative care nursing as a specialized field, aiming for it after acquiring the basic knowledge and skills of a nurse, that is, after as much clinical nursing experience as possible, is more likely to develop high quality hospice/palliative care nursing skills. It is also considered that at least 2 to 5 years of specialized nursing experience in continued hospice/palliative care practice is needed.

Many of the HPNs had training experience. HPNs with training experience scored high in most clinical nursing competencies, and the effectiveness of training was shown, as in previous research [20]-[22]. As described above, it is desirable to have specialized nursing experience with a foundation of abundant clinical nursing experience to practice nursing in hospice/palliative care. However, training for HPNs with little specialized nursing experience is effective in improving their own nursing practice, and is considered essential. Therefore, in the process of accumulating specialized nursing experience, it is desirable to create an environment in the organization so that the HPN can receive active and continuous training.

\section{Limitations of This Study and Future Issues}

There is a limit to generalization of the results of this study because clinical nursing experience and specialized nursing experience overlap. In the future, differences of certified and specialized nurses should be investigated to further clarify the expertise of hospice/palliative care.

\section{Conclusions}

In this study, the relationship between the clinical nursing competence and Nursing occupational experience of HPNs in hospice/palliative care which was clarified in the authors' previous research was examined. The results showed that the amount of clinical nursing experience as a nurse was related to clinical nursing competence in the care of end-of-life patients and worsening of symptoms. The abundance of specialized nursing experience was also related to clinical nursing competence in communication in addition to care and prediction of worsening of symptoms. Training experience was also shown to be effective for hospice/palliative care.

From these results, clinical nursing competence of HPNs in care of end-of-life patients and prediction of worsening of symptoms are possibly learned through the accumulation of clinical nursing experience as a nurse. However, HPN's clinical nursing competence in communication was suggested to be developed through nursing practice in hospice/palliative care. If general nurses aim for hospice/palliative care as a specialized field, aiming for it after acquiring the basic knowledge and skills of a nurse, that is, after abundant clinical nursing experience, is more likely to develop high quality hospice/palliative care nursing skills. It is also necessary for the organization that the HPN belongs to, to support active and continual participation in training, so that HPNs can gain quality and abundant clinical/specialized nursing experience.

\section{Acknowledgements}

The authors would like to thank all of the hospice/palliative care HPN who cooperated with this study, as well as 
the hospital directors, nursing directors and head HPN.

\section{Disclosure}

All of the coauthors declare that they have no direct conflict of interest or grant support that is directly related to the content of the study.

\section{References}

[1] Tsutsumi, K., Sekido, K. and Tanioka, T. (2014) Characteristics of Nursing Care for Terminally Ill Patients in Hospice/Palliative Care Unit. Health, 6, 2121-2128. http://dx.doi.org/10.4236/health.2014.616246

[2] Japanese Nursing Association. http://www.nurse.or.jp/nursing/education/training/plan.html

[3] Takase, M., Teraoka, S., Miyakoshi, Y. and Kawada, A. (2006) A Concept Analysis of Nursing Competence: A Review of International Literature. (In Japanese) http://www.jsnr.jp/search/docs/403404001.pdf

[4] American Nurses Association (2010) Nursing: Scope and Standards of Practice. 2nd Edition, American Nurses Publishing, Silver Spring.

[5] Matsutani, M., Miura, Y., Hirabayashi, Y., et al. (2010) Nursing Competency: Concept, Structure of Dimensions, and Assessment. Journal of St. Luke's Society of Nursing Research, 14, 18-28. http://arch.slcn.ac.jp/dspace/bitstream/10285/6257/2/2010031-gakkai14 (2)-6257.pdf

[6] O’Leary, J. (2012) Comparison of Self-Assessed Competence and Experience among Critical Care Nurses. Journal of Nursing Management, 20, 607-614. http://dx.doi.org/10.1111/j.1365-2834.2012.01394.x

[7] Tsuzi, C., Ogasawara, C., Takeda, C., et al. (2007) The Plateau Phenomena and Factors Related to the Development of Nurses’ Practical Abilities. Japanese Journal of Nursing Research, 30, 31-38. (In Japanese)

[8] Masuhara, K., Hiromi, H.U. and Tarui, E. (2007) Development of Nurses with Nursing Performance and Social Skills. Bulletin of Shimane University Faculty of Medicine, 30, 51-57. (In Japanese)

[9] Numminen, O., Meretoja, R., Isoaho, H. and Leino-Kilpi, H. (2013) Professional Competence of Practicing Nurses. Journal of Clinical Nursing, 22, 1411-1423. http://dx.doi.org/10.1111/j.1365-2702.2012.04334.x

[10] Nakanishi, M. and Ohishi, M. (2002) Nursing \& Medical Dictionary. 6th Edition, Igaku-shoin, Tokyo, 407-408. (In Japanese)

[11] Lyneham, J., Parkinson, C. and Denholm, C. (2009) Expert Nursing Practice: A Mathematical Explanation of Benner’s 5th Stage of Practice Development. Journal of Advanced Nursing, 65, 2477-2484. http://dx.doi.org/10.1111/j.1365-2648.2009.05091.x

[12] Komatsu, M., Izumi, M. and Okubo, Y. (2011) Nursing Practical Skills and Educational Issues among Nurses at Completion of Nursing Curriculum and Nurses in the First to Third Years after Graduation. Journal of Kyoto Prefectural University of Medicine, 120, 781-791. (In Japanese) http://www.f.kpu-m.ac.jp/k/jkpum/pdf/120/120-10/komatsu10.pdf

[13] Takase, M. (2013) The Relationship between the Levels of Nurses' Competence and the Length of Their Clinical Experience: A Tentative Model for Nursing Competence Development. Journal of Clinical Nursing, 22, 1400-1410. http://dx.doi.org/10.1111/j.1365-2702.2012.04239.x

[14] Rudman, A., Gustavsson, P., Ehrenberg, A., Boström, A.M. and Wallin, L. (2012) Registered Nurses’ Evidence-Based Practice: A Longitudinal Study of the First Five Years after Graduation. International Journal of Nursing Studies, 49, 1494-1504. http://dx.doi.org/10.1016/j.ijnurstu.2012.07.007

[15] Byrne, D. and McMurray, A. (1997) Caring for the Dying: Nurses’ Experiences in Hospice Care. The Australian Journal of Advanced Nursing, 15, 4-11.

[16] Johnston, B. and Smith, L.N. (2006) Nurses' and Patients' Perceptions of Expert Palliative Nursing Care. Journal of Advanced Nursing, 54, 700-709. http://dx.doi.org/10.1111/j.1365-2648.2006.03857.x

[17] Tanaka, I., Higa, H. and Yamada, K. (2012) Comparison of Clinical Nursing Competence Based on Attributes of Nurses, and Relationship between Number of Working Years, Sense of Coherence, and Spirituality. Journal of the Nursing Society of University of Toyama, 12, 81-92. (In Japanese)

[18] Braun, M., Gordon, D. and Uziely, B. (2008) Associations between Oncology Nurses’ Attitudes toward Death and Caring for Dying Patients. Oncology Nursing Forum, 37, E43-E49. http://dx.doi.org/10.1188/10.ONF.E43-E49

[19] Gama, G., Barbosa, F. and Vieira, M. (2012) Factors Influencing Nurses’ Attitudes toward Death. International Journal of Palliative Nursing, 18, 267-273. http://dx.doi.org/10.12968/ijpn.2012.18.6.267

[20] White, K.R. and Coyne, P.J. (2011) Nurses’ Perceptions of Educational Gaps in Delivering End-of-Life Care. Oncology Nursing Forum, 38, 711-717. http://dx.doi.org/10.1188/11.ONF.711-717 
[21] Montagnini, M., Smith, H. and Balistrieri, T. (2011) Assessment of Self-Perceived End-of-Life Care Competencies of Intensive Care Unit Providers. Journal of Palliative Medicine, 15, 29-36. http://dx.doi.org/10.1089/jpm.2011.0265

[22] Lee, J., Choi, M., Kim, S.S., Kim, H. and Kim, D. (2013) Korean Nurses’ Perceived Facilitators and Barriers in Provision of End-of-Life Care. International Journal of Nursing Practice, 19, 334-343. http://dx.doi.org/10.1111/ijn.12070 
Scientific Research Publishing (SCIRP) is one of the largest Open Access journal publishers. It is currently publishing more than 200 open access, online, peer-reviewed journals covering a wide range of academic disciplines. SCIRP serves the worldwide academic communities and contributes to the progress and application of science with its publication.

Other selected journals from SCIRP are listed as below. Submit your manuscript to us via either submit@scirp.org or Online Submission Portal.
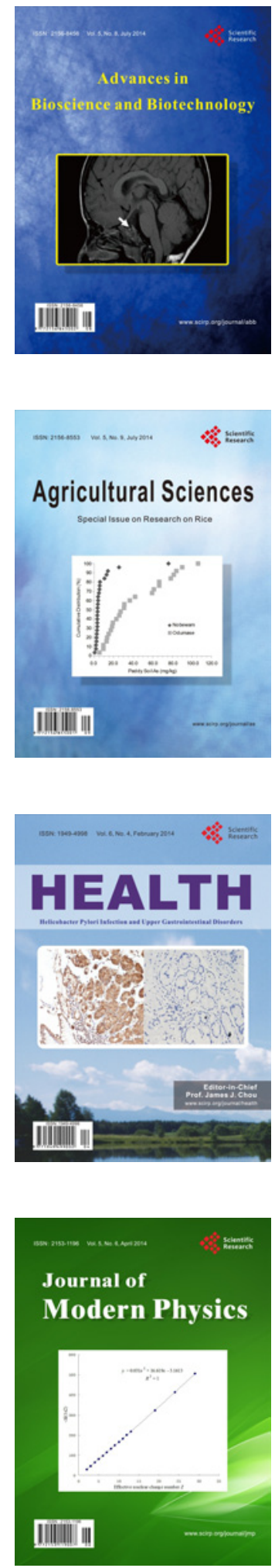
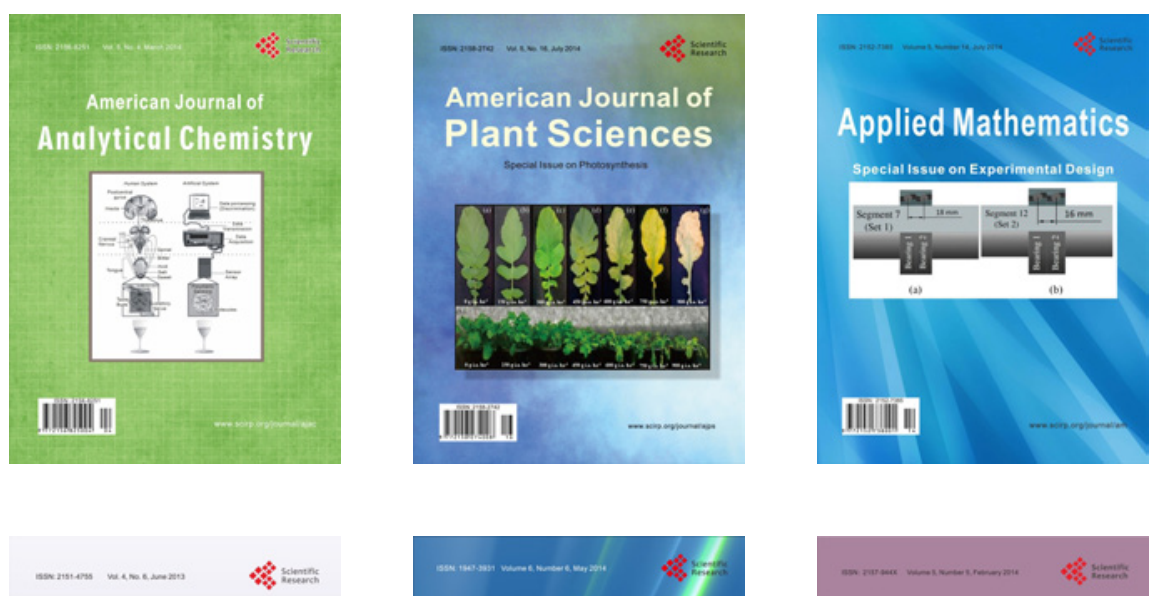

Creative Education
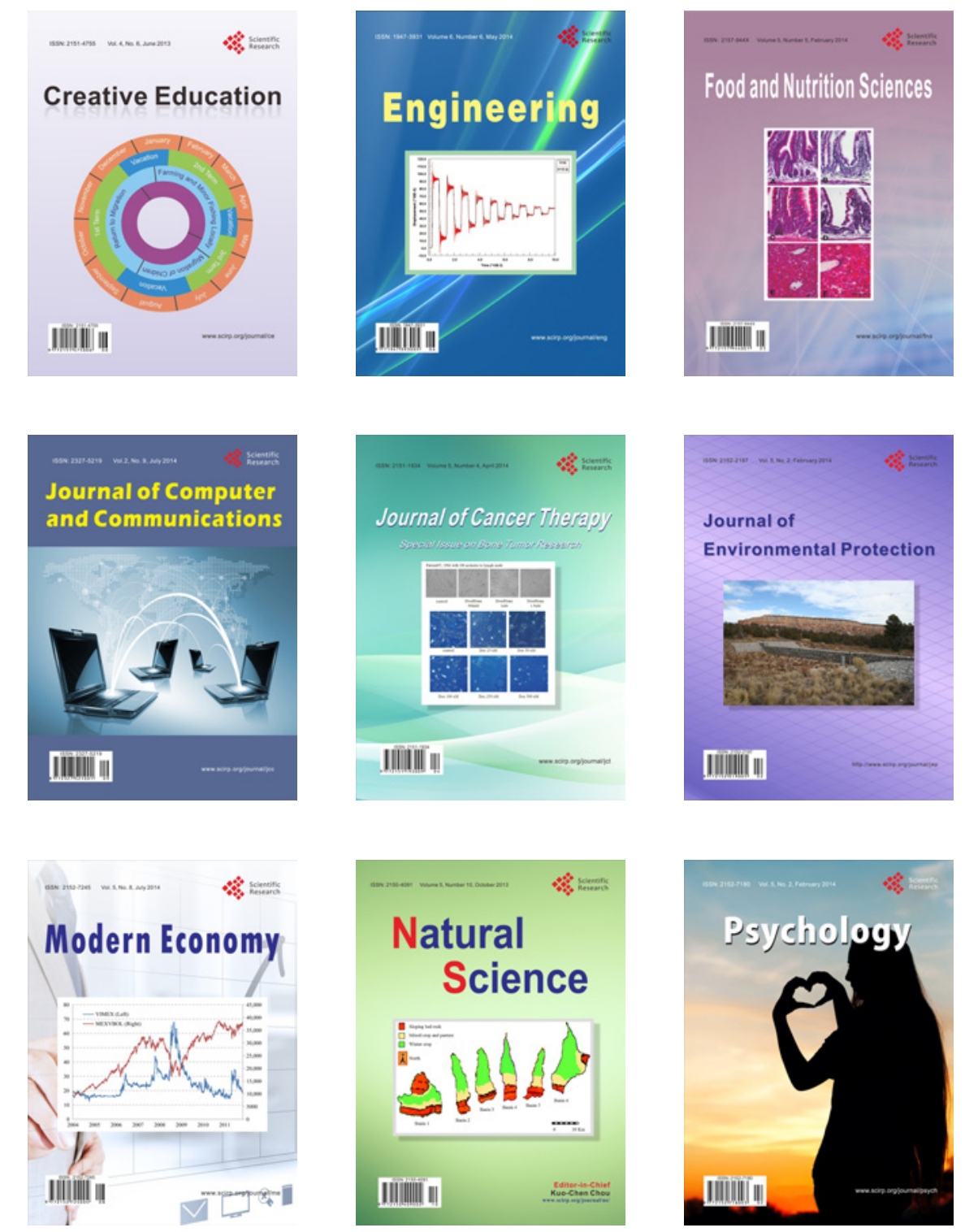